TITLE:

\title{
Electrochemically stable fluorohydrogenate ionic liquids based on quaternary phosphonium cations
}

\section{$\operatorname{AUTHOR}(S)$ :}

Kanematsu, Shunsuke; Matsumoto, Kazuhiko; Hagiwara, Rika

\section{CITATION:}

Kanematsu, Shunsuke ...[et al]. Electrochemically stable fluorohydrogenate ionic liquids based on quaternary phosphonium cations. Electrochemistry Communications 2009, 11(6): 1312-1315

\section{ISSUE DATE:}

2009-06

URL:

http://hdl.handle.net/2433/261015

\section{RIGHT:}

(C) 2009. This manuscript version is made available under the CC-BY-NC-ND 4.0 license http://creativecommons.org/licenses/by-nc-nd/4.0/.; This is not the published version. Please cite only the published version.; この論文は出版社版でありません。引用の際には 出版社版をご確認ご利用ください。 


\title{
Title
}

Electrochemically stable fluorohydrogenate ionic liquids based on quaternary phosphonium cations

\section{Authors}

Shunsuke Kanematsu, Kazuhiko Matsumoto and Rika Hagiwara*

*Corresponding author; $\quad$ Tel: $\quad+81-75-753-5822, \quad$ Fax: $+81-75-753-5906, \quad$ Email: hagiwara@energy.kyoto-u ac.jp

\section{Affiliations}

Graduate School of Energy Science, Kyoto University, Sakyo-ku, Kyoto 606-8501, Japan

\begin{abstract}
Fluorohydrogenate ionic liquids of quaternary phosphonium cations, tri- $n$-butylmethylphosphonium $\quad\left(\mathrm{P}_{4441}\right) \quad$ fluorohydrogenate, tetra- $n$-butylphosphonium $\quad\left(\mathrm{P}_{4444}\right)$ fluorohydrogenate, and tri- $n$-butyl- $n$-octylphosphonium $\left(\mathrm{P}_{4448}\right)$ fluorohydrogenate, have been synthesized by the metatheses of anhydrous hydrogen fluoride and the corresponding phosphonium chloride precursors. All the obtained salts have melting points below room temperature with a vacuum-stable composition of $\mathrm{P}_{444 m}(\mathrm{FH})_{2.3} \mathrm{~F}(m=1,4$, and 8$)$ and were characterized by density, conductivity, and viscosity measurements. Linear sweep voltammetry with a glassy carbon working electrode shows that the $\mathrm{P}_{444 m}(\mathrm{FH})_{2.3} \mathrm{Fs}$ have wide electrochemical windows exceeding $5.2 \mathrm{~V}$. In particular, $\mathrm{P}_{4441}(\mathrm{FH})_{2.3} \mathrm{~F}$ has an electrochemical window of $6.0 \mathrm{~V}$, which is the widest among fluorohydrogenate ionic liquids reported to date. The thermal stability of these ionic liquids is also improved compared to the salts of $N$-heterocyclic ammonium cations.
\end{abstract}

\section{Keywords}

Ionic liquid; molten salt; Quaternary phosphonium salt; Fluorohydrogenate, Electrochemical window; Thermal stability 


\section{Introduction}

Room-temperature ionic liquids (RTILs, also called room-temperature molten salts) composed of alkylated ammonium cations and various chloro- or fluoroanions have been intensively studied for some decades. Characteristic features often found in RTILs are their high ionic conductivity, extremely low vapor pressure, non-flammability, high thermal and electrochemical stability, and wide liquid temperature range [1-6]. Because of their excellent properties, a number of research groups have looked to apply RTILs to fields such as electrochemistry and organic chemistry [1,3,6-8]. Although ammonium-based cations such as tetraalkylammonium, imidazolium, pyridinium and pyrrolidinium are often used to synthesize RTILs, research on phosphonium-based cations has also become of interest in terms of application to electrochemical systems [9-12]. Phosphonium-based cations have better thermal, chemical, and electrochemical stabilities compared to ammonium-based RTILs, which is important when trying to improve the safety and power density of electrochemical devices such as electric double-layer capacitors. Furthermore, some phosphonium ionic liquids exhibit lower melting points, lower viscosities, and higher conductivities than the corresponding ammonium analogues.

Ionic liquids based on fluorohydrogenate anions $\left((\mathrm{FH})_{n} \mathrm{~F}^{-}\right)$, prepared by the reaction of $N$-heterocyclic ammonium chloride with anhydrous hydrogen fluoride, exhibit higher conductivities and lower viscosities than other RTILs (e.g., $10^{2} \quad \mathrm{mS} \quad \mathrm{cm}^{-1}$ and $4.9 \mathrm{cP}$ for 1-ethyl-3-methylimidazolium fluorohydrogenate $\left(\operatorname{EMIm}(\mathrm{FH})_{2.3} \mathrm{~F}\right)$ ), whereas their electrochemical windows are relatively narrow compared with those for RTILs based on fluoroanions such as $\mathrm{BF}_{4}^{-}$, $\mathrm{PF}_{6}{ }^{-}$, and $\mathrm{N}\left(\mathrm{SO}_{2} \mathrm{CF}_{3}\right)_{2}^{-}[13]$.

The fluorohydrogenate ionic liquids (FHILs) reported to date have been limited to $N$-heterocyclic ammonium cation-based salts [13-16]. The combination of fluorohydrogenate anions with chemically stable phosphonium cations would have interesting potential for the production of safe electrolytes with high conductivity, electrochemical and thermal stability, as well as low melting 
point. In the present study, we describe the synthesis and characterization of the following FHILs based on quaternary phosphonium cations: tri- $n$-butylmethylphosphonium $\left(\mathrm{P}_{4441}\right)$ fluorohydrogenate, tetra- $n$-butylphosphonium $\left(\mathrm{P}_{4444}\right)$ fluorohydrogenate, and tri- $n$-butyl- $n$-octylphosphonium $\left(\mathrm{P}_{4448}\right)$ fluorohydrogenate. The relationships between the properties of the salts and the molecular weight or symmetry of the cation are discussed.

\section{Experimental}

The quaternary phosphonium chlorides obtained from Nippon Chemical Industry Co. Ltd. were dried at $120^{\circ} \mathrm{C}$ under vacuum for one day prior to use. The fluorohydrogenate ionic liquids were prepared by the reaction of a large excess of anhydrous $\mathrm{HF}$ and $\mathrm{P}_{444 m} \mathrm{Cl}$ as previously described [13,14]. Addition of fresh HF and elimination of volatile gases were repeated until the ionic liquids did not precipitate $\mathrm{AgCl}$ by addition of aqueous $\mathrm{AgNO}_{3}$. The products were identified by elemental analyses and ${ }^{1} \mathrm{H},{ }^{19} \mathrm{~F}$ and ${ }^{31} \mathrm{P}$ NMR spectroscopy. The physical, thermal, and electrochemical properties were measured as previously described $[13,14]$.

\section{Results and discussion}

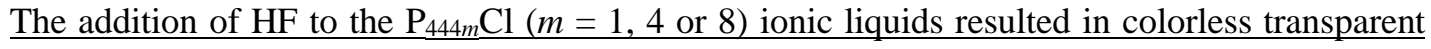
RTILs that were vacuum stable. The HF composition is formulated as $\mathrm{P}_{444 m}(\mathrm{FH})_{2.3} \mathrm{~F}$ as obtained for previously reported FHILs based on $N$-heterocyclic ammonium cations, which is consistent with results from anion mixing $\left((\mathrm{FH})_{2} \mathrm{~F}^{-}:(\mathrm{FH})_{3} \mathrm{~F}^{-}=7: 3\right)$. These results differ from those for linear tetraalkylammonium fluorohydrogenate systems. For example, when HF-rich linear tetraalkylammonium fluorohydrogenate salts are evacuated at room temperature, HF is usually eliminated and $(\mathrm{FH})_{2} \mathrm{~F}^{-}$or $\mathrm{FHF}^{-}$salts are crystallized [17]. 
Selected physical properties of $\mathrm{P}_{444 m}(\mathrm{FH})_{2.3} \mathrm{~F}$ are summarized in Table 1 along with the data for some other RTILs for comparison. The Arrhenius plots of conductivity and viscosity for $\mathrm{P}_{444 m}(\mathrm{FH})_{2.3} \mathrm{Fs}$ show an almost linear dependence over the measured temperature range (Fig. 1). As the molecular weight increases, the viscosity increases and the conductivity decreases, as is seen in $N$-heterocyclicammonium FHILs. Although it is often pointed out that the high symmetry of an ion leads to a high melting point and a high viscosity $[19,20]$, the viscosity of $\mathrm{P}_{4444}(\mathrm{FH})_{2.3} \mathrm{~F}$ is not particularly high among the $\mathrm{P}_{444 m}(\mathrm{FH})_{2.3} \mathrm{Fs}$. The present $\mathrm{P}_{444 m}(\mathrm{FH})_{2.3} \mathrm{~F}$ ionic liquids are more viscous and less conductive than the other non-phosphonium FHILs and their activation energies are higher than those of the ammonium FHILs (e.g., the conductivity and viscosity of EMIm(FH) $)_{2.3} \mathrm{~F}$ are 12.7 and $10.1 \mathrm{~kJ} \mathrm{~mol}^{-1}$, respectively) [13-15]. This behavior is ascribed to an increase in van der Waals interactions between cations caused by the introduction of the long alkyl side-chains $[21,22]$. Nevertheless, $\mathrm{P}_{4444}(\mathrm{FH})_{2.3} \mathrm{Fs}$ are far less viscous and more conductive than other phosphonium-based ionic liquids.

Differential scanning calorimetric curves for $\mathrm{P}_{444 m}(\mathrm{FH})_{2.3} \mathrm{Fs}$ are shown in Fig. 2. In the heating process of $\mathrm{P}_{4441}(\mathrm{FH})_{2.3} \mathrm{~F}$, peaks assigned to glass transition and melting are observed, without the appearance of the peak corresponding to crystallization appearing between the two states. This behavior can be explained by the following reasoning. In the cooling process, only $\mathrm{P}_{4441}(\mathrm{FH})_{2} \mathrm{~F}$ crystallizes at $216 \mathrm{~K}$, and $\mathrm{P}_{4441}(\mathrm{FH})_{3} \mathrm{~F}$ forms a glass phase at $167 \mathrm{~K}$. In the heating process, the glass transition of $\mathrm{P}_{4441}(\mathrm{FH})_{3} \mathrm{~F}$ occurs at $170 \mathrm{~K}$, followed by the melting of $\mathrm{P}_{4441}(\mathrm{FH})_{2} \mathrm{~F}$ at $248 \mathrm{~K}$. The extension of the alkyl side-chain on the cation usually results in lowering of the melting point of the salt, but $\mathrm{P}_{4444}(\mathrm{FH})_{2.3} \mathrm{~F}$ was entirely melted at a higher temperature than $\mathrm{P}_{4441}(\mathrm{FH})_{2.3} \mathrm{~F}$, which is probably due to the high symmetry of the $\mathrm{P}_{4444}{ }^{+}$cation, enabling closer packing of the ions in the solid state. For $\mathrm{P}_{4448}(\mathrm{FH})_{2.3} \mathrm{~F}$, only a glass transition peak is observed in the heating process. Thermogravimetric curves for $\mathrm{P}_{444 m}(\mathrm{FH})_{2.3} \mathrm{Fs}$ are shown in Fig. 3 along with the curves for 1-ethyl-3-methylimidazolium fluorohydrogenate $\left(\mathrm{EMIm}(\mathrm{FH})_{2.3} \mathrm{~F}\right)$, 1-butyl-3-methylimidazolium fluorohydrogenate $\quad\left(\mathrm{BMIm}(\mathrm{FH})_{2.3} \mathrm{~F}\right), \quad$ and $\quad N$-ethyl- $N$-methylpyrrolidinium fluorohydrogenate 
$\left(\operatorname{EMPyr}(\mathrm{FH})_{2.3} \mathrm{~F}\right)$ for comparison. The $\mathrm{P}_{444 m}(\mathrm{FH})_{2.3} \mathrm{~F}$ ionic liquids monotonously lose their weight at 300 to $520 \mathrm{~K}$ due to the reversible elimination of $\mathrm{HF}$ from the $(\mathrm{FH})_{n} \mathrm{~F}^{-}$anion, followed by the irreversible decomposition from around $530 \mathrm{~K}$. The improved thermal stability resulting from the introduction of phosphonium-based cations is demonstrated by the weight loss process of $\mathrm{P}_{444 m}(\mathrm{FH})_{2.3} \mathrm{~F}$ occurring at higher temperatures than those of the $N$-heterocyclic ammonium salts. However, the irreversible decomposition temperatures of the $\mathrm{P}_{444 m}(\mathrm{FH})_{2.3} \mathrm{Fs}$ are lower by $\sim 100 \mathrm{~K}$ than those of phosphonium-based RTILs with other cations [9,12]. One explanation for this result is that compounds such as $\mathrm{P}_{444 m} \mathrm{FHF}$, remaining after volatilization of $\mathrm{HF}$ below $\sim 520 \mathrm{~K}$, easily decompose due to the high nucleophilicity of $\mathrm{FHF}^{-}$.

Linear sweep voltammograms of glassy carbon and platinum electrodes in $\mathrm{P}_{444 m}(\mathrm{FH})_{2.3} \mathrm{Fs}$ are shown in Fig. 4. The anode and cathode limits are determined as the potentials at which the absolute value of the current density exceeds $0.5 \mathrm{~mA} \mathrm{~cm}^{-2}$ at a scan rate of $10 \mathrm{mV} \mathrm{s}^{-1}$. For the glassy carbon electrode, $\mathrm{P}_{444 m}(\mathrm{FH})_{2.3} \mathrm{Fs}$ exhibit a wide electrochemical window exceeding $5.2 \mathrm{~V}$. In particular, $\mathrm{P}_{4441}(\mathrm{FH})_{2.3} \mathrm{~F}$ gives an electrochemical window of $6.0 \mathrm{~V}$, which is the widest among previously reported FHILs [13-16], reflecting the high electrochemical stability of the phosphonium-based FHILs. The cathode limits of the $\mathrm{P}_{444 m}(\mathrm{FH})_{2.3} \mathrm{Fs}$ are around $-3.0 \mathrm{~V} v s . \mathrm{Fc} / \mathrm{Fc}^{+}$and are slightly more negative than those of non-aromatic cation-based FHILs. The anode limits of the $\mathrm{P}_{444 m}(\mathrm{FH})_{2.3} \mathrm{Fs}$ vary from $2.0-2.9 \mathrm{~V} v s . \mathrm{Fc} / \mathrm{Fc}^{+}$, and shift to lower potential with an increase in the length of the side-chain. This trend is not observed in phosphonium ILs based on the amide ion $[12,18]$. For the platinum working electrode, a cathodic wave, which is absent in the case of a glassy carbon electrode, is observed from $-1.0 \mathrm{~V}$ vs. $\mathrm{Fc} / \mathrm{Fc}^{+}$. This behavior can be explained by the lower overpotential for the hydrogen gas evolution reaction from $(\mathrm{FH})_{n} \mathrm{~F}^{-}$on a platinum electrode as compared with that on a glassy carbon electrode. The other reduction wave observed from $-3.0 \mathrm{~V} v s$. $\mathrm{Fc} / \mathrm{Fc}^{+}$is ascribed to decomposition of the cation, which is probably the same reaction as that which occurs at the cathode limit for a glassy carbon electrode. The more negative anode limit potentials observed for the platinum electrode are thus due to either the low overpotential for anodic reactions 
on a platinum electrode or anodic dissolution of platinum.

\section{Conclusions}

Fluorohydrogenate salts of quaternary phosphonium cations were synthesized and their physicochemical properties were investigated. Thermogravimetry and linear sweep voltammetry revealed that the $\mathrm{P}_{444 m}(\mathrm{FH})_{2.3} \mathrm{Fs}$ are more thermally and electrochemically stable than $N$-heterocyclicammonium-based FHILs. In particular, the high electrochemical stability and low viscosity of $\mathrm{P}_{4441}(\mathrm{FH})_{2.3} \mathrm{~F}$ are favorable for applications such as electrolytes within electric double layer capacitors. Introduction of other functional groups to the phosphonium cation would be an interesting be an interesting avenue to obtain FHILs with specific functionalities.

\section{Acknowledgement}

The authors are grateful to Dr. Tsunashima of Nippon Chemical Industrial Co. Ltd. for the supply of phosphonium chlorides and his valuable advice. This work was supported by a Grant-in-Aid for Scientific Research for Priority Area "Science of Ionic Liquids" of Ministry of Education, Culture, Sports, Science and Technology. 


\section{References}

[1] T. Welton, Chem. Rev. 99 (1999) 2071.

[2] R. Hagiwara, Y. Ito, J. Fluorine Chem. 105 (2000) 221.

[3] R. D. Rogers, K. R. Seddon, Science, 302, (2003) 792.

[4] P. Bonhôte, A.-P. Dias, N. Papageorgiou, K. Kalyanasundaram, M. Grätzel, Inorg. Chem. 35 (1996) 1168.

[5] D. R. McFarlane, J. Sun, J. Golding, P. Meakin, M. Forsyth, Electrochim. Acta 45 (2000) 1271.

[6] H. Matsumoto, M. Yanagida, K. Tanimoto, M. Nomura, Y. Kitagawa, Y. Miyazaki, Chem. Lett. (2000) 922.

[7] R. Hagiwara, T. Nohira, K. Matsumoto, Y. Tamba, Electrochem. Solid-State Lett. 8 (2005) A231.

[8] C. Nanjundiah, S. F. McDevitt, V. R. Koch, J. Electrochem. Soc. 144 (1997) 3392.

[9] C. J. Bradaric, A. Downard, C. Kennedy, A. J. Robertson, Y. Zhou, Green Chem. 5 (2003) 143.

[10] R. E. Del Sesto, C. Corley, A. Robertson, J. S. Wilkes, J. Organomet. Chem. 690 (2005) 2536.

[11] J. Kagimoto, K. Fukumoto, H. Ohno, Chem. Commun. 2006, 2254.

[12] K. Tsunashima, M. Sugiya, Electrochem. Commun. 9 (2007) 2353 and references therein.

[13] R. Hagiwara, K. Matsumoto, Y. Nakamori, T. Tsuda, Y. Ito, H. Matsumoto, K. Momota, J. Electrochem. Soc. 150 (2003) D195.

[14] K. Matsumoto, R. Hagiwara, Y. Ito, Electrochem. Solid-State Lett. 7 (2004) E41.

[15] R. Ueno, K. Matsumoto, R. Hagiwara, Abst. 37th Symp. on Molten Salt Chem. (2005) p.59.

[16] M. Yamagata, S. Konno, K. Matsumoto, R. Hagiwara, Electrochem. Solid-State Lett., in press.

[17] D. Mootz, D. Boenigk, Z. Anorg. Allg. Chem. 544 (1987) 159.

[18] K. Tsunashima, M. Sugiya, Electrochemistry 75 (2007) 734.

[19] D. R. McFarlane, J. Sun, J. Golding, P. Meakin, M. Forsyth, Electrochim. Acta 45 (2000) 1271. 
[20] H. Matsumoto, H. Sakaebe, K. Tatsumi, J. Power Sources 146 (2005) 45.

[21] H. Tokuda, K. Hayamuzu, K. Ishii, M. A. B. H. Susan, M. Watanabe, J. Phys. Chem. B 109 (2005) 6103.

[22] J. D. Holbrey, K. R. Seddon, J. Chem. Soc. Dalton Trans. 1999, 2133. 
Table 1

Selected physical and electrochemical properties of RTILs

\begin{tabular}{lccccc}
\hline \multicolumn{1}{c}{ RTIL } & $\mathrm{FW}$ & $T_{\mathrm{m}}\left(T_{\mathrm{g}}\right)$ & $\rho$ & $\eta$ & $\sigma$ \\
& & $/ \mathrm{K}$ & $/ \mathrm{g} \mathrm{cm}^{-3}$ & $/ \mathrm{cP}$ & $/ \mathrm{mS} \mathrm{cm}^{-1}$ \\
\hline $\mathbf{P}_{4441}(\mathbf{F H})_{2.3} \mathbf{F}$ & 282 & $249,(169)$ & 0.969 & 36 & 6.0 \\
$\mathbf{P}_{4444}(\mathbf{F H})_{2.3} \mathbf{F}$ & 324 & 239,255 & 0.954 & 47 & 3.7 \\
$\mathbf{P}_{4448}(\mathbf{F H})_{2.3} \mathbf{F}$ & 381 & $(174)$ & 0.934 & 74 & 1.5 \\
$\mathrm{HexMPyr}$ & $235)_{2.3} \mathrm{~F}^{[15]}$ & - & 0.993 & 18.0 & 23.7 \\
$\mathrm{P}_{4441} \mathrm{~N}\left(\mathrm{SO}_{2} \mathrm{CF}_{3}\right)_{2}[18]$ & 498 & 289 & 1.28 & 207 & 0.416 \\
$\mathrm{P}_{4448} \mathrm{~N}\left(\mathrm{SO}_{2} \mathrm{CF}_{3}\right)_{2}{ }^{[18]}$ & 596 & $<223$ & 1.18 & 250 & 0.268 \\
$\mathrm{P}_{4448} \mathrm{BF}_{4}[18]$ & 402 & $<223$ & 1.02 & 1240 & 0.069 \\
\hline
\end{tabular}

FW: formula weight, $T_{\mathrm{m}}$ : melting point, $T_{\mathrm{g}}$ : glass transition temperature, $\rho$ : density at $298 \mathrm{~K}, \eta$ : viscosity at $298 \mathrm{~K}, \sigma$ : conductivity at $298 \mathrm{~K}$. 


\section{Figure captions}

Fig. 1: Arrhenius plots of (a) conductivity and (b) viscosity for $\mathrm{P}_{444 m}(\mathrm{FH})_{2.3} \mathrm{Fs} . E_{\mathrm{a}}$ : activation energy.

Fig. 2: DSC curves of $\mathrm{P}_{444 m}(\mathrm{FH})_{2.3} \mathrm{Fs}$ in pressure-resistant cells made of stainless steel. Scan rate: 5 $\mathrm{K} \min ^{-1}$.

Fig. 3: TG curves of FHILs in platinum cells. Scan rate: $10 \mathrm{~K} \mathrm{~min}^{-1}$.

Fig. 4: Linear sweep voltammograms of a glassy carbon electrode (solid lines) and a platinum electrode (dotted lines) in $\mathrm{P}_{444 m}(\mathrm{FH})_{2.3} \mathrm{Fs}$ at $298 \mathrm{~K}$. Counter electrode: glassy carbon, reference electrode: Ag wire immersed in 1-ethyl-3-methylimidazolium tetrafluoroborate containing $0.05 \mathrm{M}$ $\mathrm{AgBF}_{4}$. Potentials were referenced to the potential of the ferrocene/ferrocenium redox couple. Scan rate: $10 \mathrm{mV} \mathrm{s}^{-1}$. 

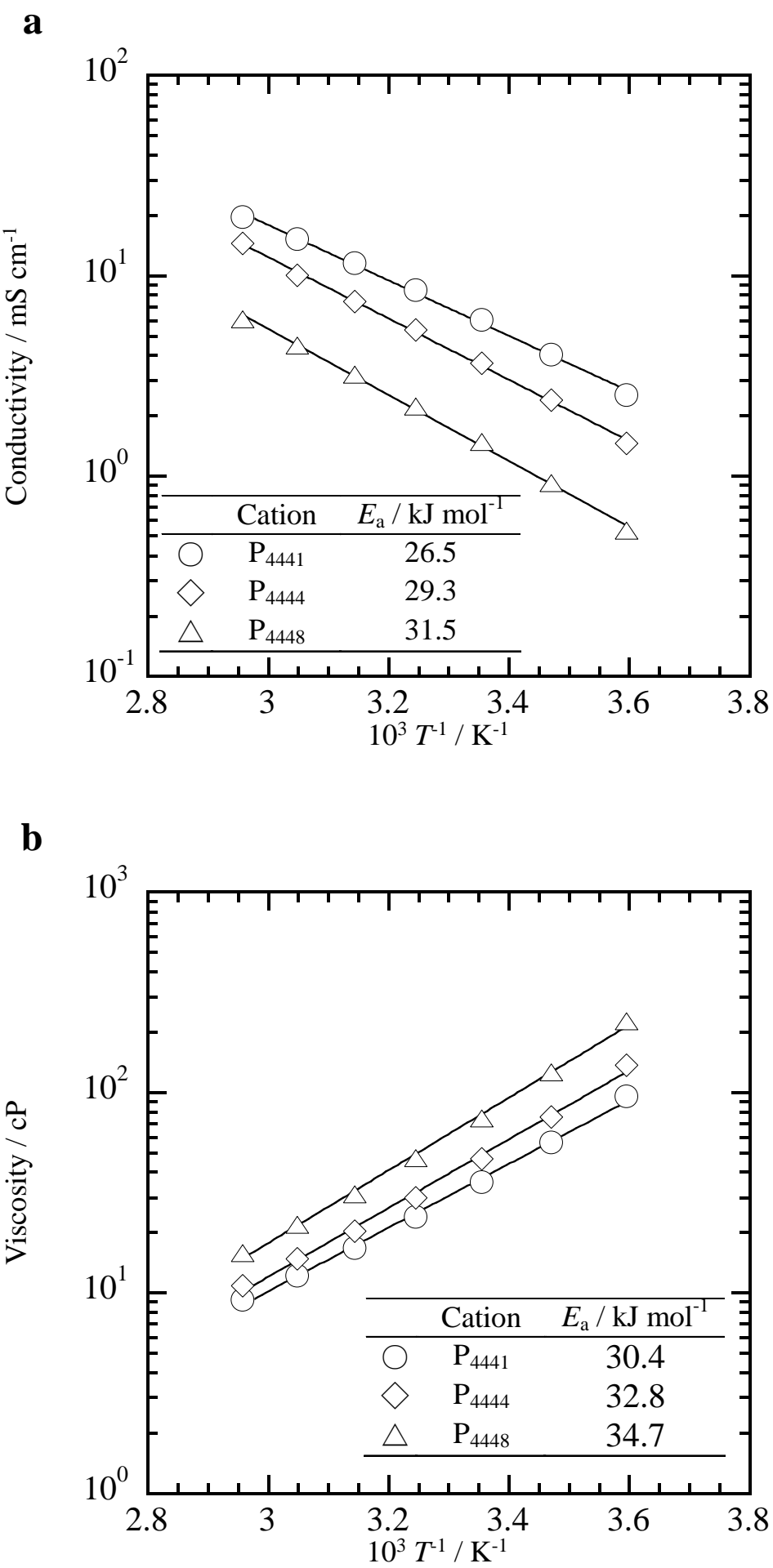

Fig. 1: 


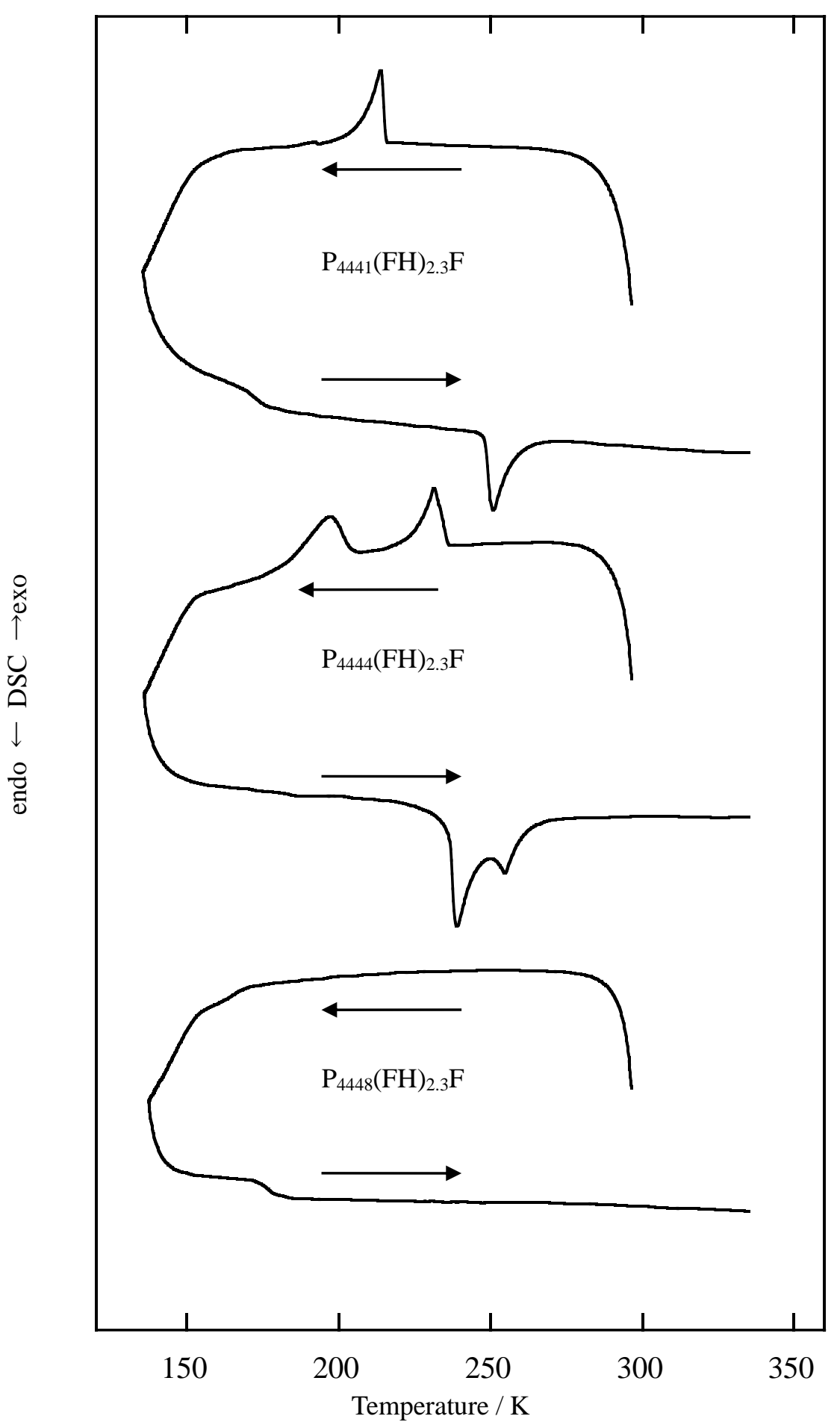

Fig. 2: 


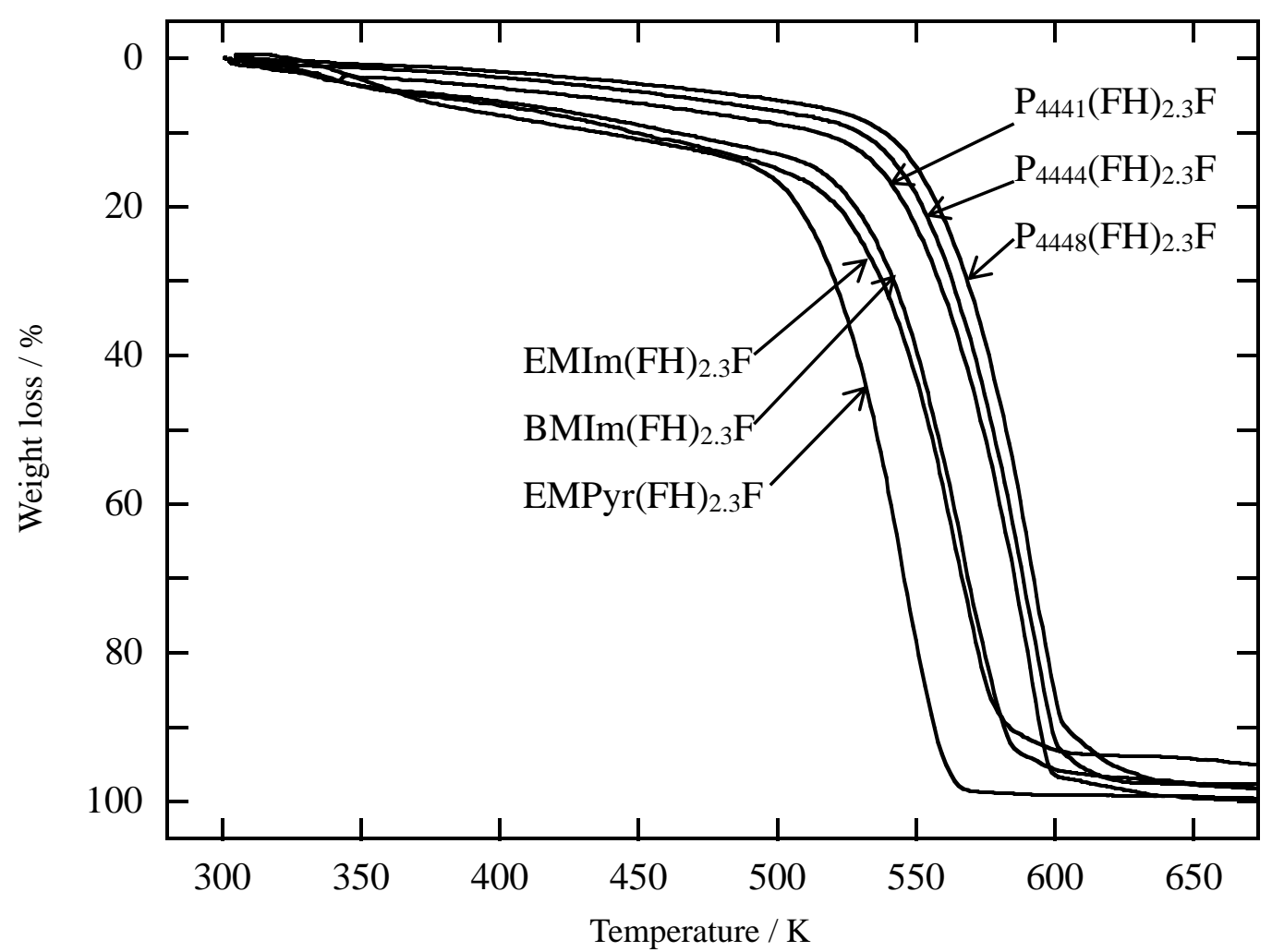

Fig. 3: 


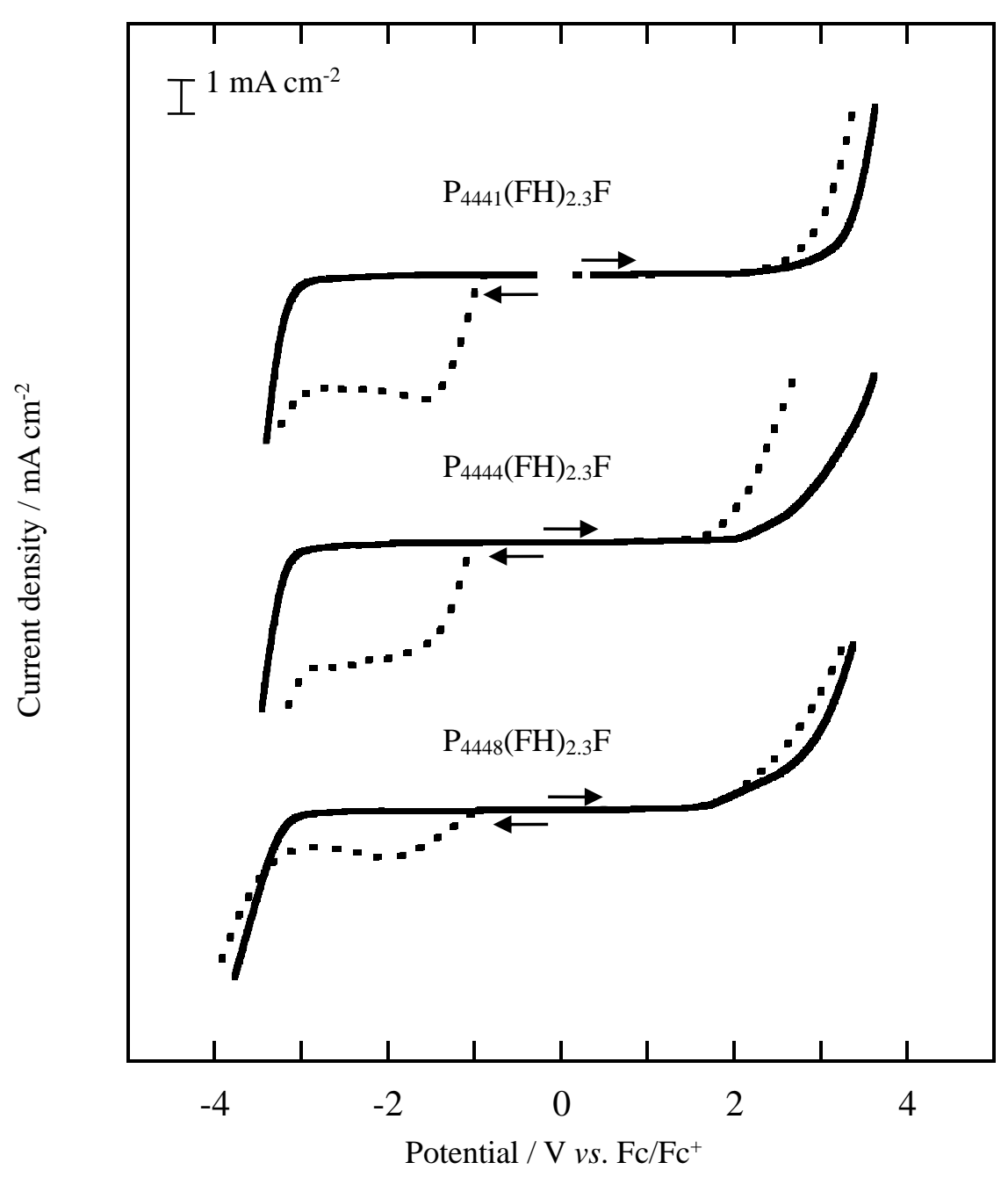

Fig. 4: 